\title{
Factors that motivated medical students at abia state university uturu to choose medicine as a career
}

\begin{abstract}
Background: People have various reasons for choosing medicine as a career. We decided to carry out a questioner survey among students in Abia State University Uturu to find out the factors that influenced them to choose medicine as a career.

Materials and methods: A questionnaire- based study was carried out among clinical students of 400.500 and 600 levels. The information obtained was analyzed by simple impositions.

Results: There were 188 respondents. 106(56.4\%).were males, while 82(43.6\%) were females. The desire to save life was the strongest motivating factor in $150(79.8 \%)$, while peer pressure was the least motivating factor in $9(4.8 \%)$ of the study population. $49(26.1 \%)$ of the respondents strongly agree that economic reasons was their motivating factor. $122(64.9 \%)$ respondents strongly agree that interest in medicine was their motivating factor.
\end{abstract}

Conclusion: The desire to save life is the strongest motivating factor to choose medicine as a career, while peer pressure was the least motivating factor.
Volume I Issue 4 - 2017

\section{Otuka Oai,' Eleweke N,' Oworu O² \\ 'Department of Surgery, Abia State University, Nigeria ${ }^{2}$ Huddersfield Royal Infirmary, UK}

Correspondence: Otuka Oai, Ophthalmology Unit, Department of Surgery, Abia State University Teaching Hospital, Uturu, Nigeria, Email elshaddai_2005@yahoo.com

\footnotetext{
Received: November 01, 2017 | Published: December 12, 2017
}

Keywords: motivation, study, medicine

\section{Introduction}

Medicine is a noble profession which many people want to pursue for many reasons ranging from economic social and desire to help mankind. So many factors motivate people to choose medicine as a career.

Motivation is an internal state that arouses, directs and maintains and sustains goal-oriented behaviour. ${ }^{1}$ In this questionnaire-based study we want to find what motivated a group of medical students to choose medicine as a career.

\section{Methodology}

This was a questionnaire based population study. Questionnaires were distributed to three levels of clinical students in Abia State University, Uturu.

The data in the questionnaire included the following
a) The love of science
b) To save life
c) Sickness in childhood
d) Interest in medicine
e) Grew up in the midst of medical personnel
f) Social status
g) Economic reasons
h) Curiosity about human life
i) It permits learning

j) It is challenging

k) Job security

1) Close relative has an illness or died from an illness

m) Pressure from family members

n) Pressure from friends

o) Pressure from community

p) To be practical in life

q) Because there is no physician in my family community

r) Any other

Respondents were encouraged to choose any number of the above options that influenced their decision to study medicine. The possible responses to each of the questions above were:
i. Strongly agree.
ii. Weakly agree.
iii. Strongly disagree.
iv. Weakly disagree.
v. I do not know.

The data was collated and analysed by manual calculations.

\section{Results}

The data collected was represented in the table below (Table 1) 
Table I Responses to factors that motivated the choice of medicine as a carrier

\begin{tabular}{llllll}
\hline Questions & A & B & C & D & E \\
\hline The Love of Sciences & 100 & 61 & 11 & 9 & 7 \\
To Save Life & 150 & 31 & 3 & 3 & 1 \\
Sickness in Childhood & 27 & 45 & 84 & 16 & 16 \\
Interest in Medicine & 122 & 43 & 12 & 5 & 6 \\
Grew Up in the Midst of Medical & 30 & 33 & 83 & 26 & 16 \\
Personnel & 32 & 56 & 62 & 29 & 9 \\
Social Status & 49 & 53 & 56 & 22 & 8 \\
Economic Reasons & 63 & 53 & 34 & 25 & 13 \\
Curiosity about Life & 80 & 61 & 20 & 17 & 10 \\
It Permits Learning & 81 & 54 & 31 & 13 & 9 \\
It is Challenging & 73 & 62 & 30 & 17 & 6 \\
Job Security & 30 & 21 & 86 & 27 & 24 \\
Close Relative had an IIIness or Died & & & & & \\
of an Illness & 14 & 29 & 105 & 24 & 16 \\
Pressure from Family & 9 & 20 & 120 & 25 & 14 \\
Pressure from Friends & 13 & 29 & 105 & 25 & 16 \\
Pressure from Community & 72 & 56 & 31 & 14 & 15 \\
To be Practical in Life & 23 & 25 & 100 & 30 & 10 \\
There is no Physician in My Family & & & & &
\end{tabular}

Key:
a) Strongly agree
b) Weakly agree
c) Strongly disagree
d) Weakly disagree
e) I do not know

A total of 188 students replied to the questionnaire (Table 2).

Table 2 Distribution of response by sex

\begin{tabular}{ll}
\hline Sex distribution & Against response \\
\hline Sex & No \\
\hline Male & $106(56.4 \%)$ \\
Female & $82(43.6 \%)$ \\
\hline
\end{tabular}

Majority of the respondents $150(79.8 \%)$. Strongly agree that the desire to save life was the motivating factor to choose medicine as a career. In 49(26.1\%) of the respondents strongly agree that economic reasons was their motivating factor to choose medicine as a career. $122(64.9 \%)$ responders strongly agree that interest in medicine was their motivating factor. Community pressure in $3(6.92 \%)$ and peer pressure in $9(4.79 \%)$ were the least motivating factors.

\section{Discussion}

Many factors motivate people in their choice of career. The factors range from economic, peer pressure, family pressure or sheer interest. According to Paul $\mathrm{R}$ kleingenna et al. ${ }^{1}$ motivation is an internal state that arouses, directs and sustains goal oriented behaviour.

Educational psychologists ${ }^{2}$ are interested in motivation because of the crucial role it plays in student learning. Motivation has several effects on how students learn and towards subject matter how they behave. It can:

\section{Direct behavior towards a particular goal \\ II. Lead to increased effort and energy \\ III. Increase initiation of and persistence of activities \\ IV. Enhance cognitive processing \\ V. Determine what consequences are reinforcing}

\section{Lead to improved performance}

Students are not always motivated therefore they sometimes need situated motivation which is found in the environmental condition that the teacher creates. If teachers decide to extrinsically reward productive students' behaviour they may find it difficult to extricate from that path. Consequently, student's dependency on extrinsic rewards represents one of the greatest distractors from their rise in the class room. ${ }^{3}$

We have looked at the factors that motivated our students at Abia State University to choose medicine as a career. We found that most of our students $150(79.8 \%$ ) had the desire to save life as the strongest motivating factor while peer pressure $9(4.8 \%)$ was the least motivating factor.

Similar work done by Thakur et al. ${ }^{3}$ among medical students in Nepal, India found out that what motivated $73 \%$ of these medical students to choose medicine as a career is to provide service to the sick and to use the medical facilities available in the country and lessen the number of sick people seeking help from faith healers.

Dr Ubah J of Ladoke University Oshogbo found almost all the students picked the option of life saving and sympathy for the sick, $(98.8 \%)$ and $81(97.6 \%)$ respectively. ${ }^{4}$ Various authors found out that the factors that influence the decisions to choose medicine as career are multiple ranging from individuals characteristics, perceived benefits and attractiveness of particular medicine speciality and factors associated with medical school curricula, such as experience of chosen speciality. ${ }^{5-14}$

In comparison with dental students, medical students manifested a more professional attitude in which altruism and intellectual challenge constituted central motivating factors. By contrast, dental students demonstrated more of a commitment to personal and financial gain. ${ }^{15}$ Sharon et al. ${ }^{16}$ noted that research and publication by medical student in medical school are associated with a career in academic medicine. The desire to teach, conduct research, and the intellectual stimulation and challenge provided in academia may also persuade people to choose this career path. The influence of a role model or a mentor was reported by physicians to impact their decision making. Choosing medicine as a career Saadah Sulong et al. ${ }^{17}$ found that Ireland medical student were overwhelmingly motivated by desire to work with, and help, people, along with a desire to cure and prevent disease. Motivations to study medicine include family influence altruistic reasons and a variety of personal/social factors such as intellectual satisfaction, prestige and financial security and parental expectations 
from the study done by Professor Thong ${ }^{18}$ suggests that motivations to study medicine include family influence, altruistic reasons and a variety of personal/social factors such as intellectual satisfaction, prestige and financial security and parental expectations.

\section{Conclusion}

In this study the desire to save life is the strongest motivating factor to choose medicine as a career, while peer pressure was the least motivating factor. Most people that choose medicine as a carrier in life have a sincere desire to help mankind to alleviate suffering and to prolong life. Therefore they should be provided with an enabling environment to enhance as well as motivate their primary intrinsic factors.

\section{Acknowledgements}

We remain grateful to the almighty God who saw us through to the end of this research.

We are forever indebted to the medical students who responded to all our quetionnaires without whom it will be impossible to carry out this work.

I also wish to appreciate Eke-Otuka Uzochukwu for his efforts in making this article come through and Miss Chinonyerem Gloria Eleweke, we are forever grateful.

\section{Conflicts of interest}

The author declares no conflict of interest.

\section{References}

1. Paul R Kleinginne, Anne M Kleinginne. A categorized list of motivation definitions with a suggestion for a consensual definition. Motivation and emotion. 1981;5(3):263-291.

2. Williams RL, Stockdale SL. Classroom motivation strategies for prospective teachers. The teacher educator. 2004;39(3):212-230.

3. Amarnath Thakur, Gita Ashokraj, Shakhar Koirala. Medicine as a career choice: Motivating factors in Nepalese medical students. $J$ insti Med. 1999:21(1\&2).

4. Ubah JN. Why Study Medicine? Unique Research Journal of Medicine and Medical Sciences. 2014;2(7):88-91.

5. Cleland JA, Johnston PW, Anthony M, et al. A survey of factors influencing career preference in New- entrant and existing medical students from UK medical schools. BMC Med Educ. 2014;14:151.
6. McManus IC, Lefford F, Furnham AF, et al. Career preference and personality differences in medical school applicants. Psych Health Med. 1996;1(3):235-248.

7. Soethout MBM, Heymans MW, TenCate OJ. Career preference and medical students' biographical characteristics and academic achievement. Medical Teacher. 2008;30(1):e15-e22.

8. Vaidya NA, SIerles FS, Raida MD, et al. Relationship between specialty choice and medical student temperament and character assessed with Cloninger Inventory. Teach Learn Med. 2004;16(2):150-156.

9. Arnold MW, Patterson AF, Tang AS. Has implementation of the 80-hour work week made a career in surgery more appealing to medical students? The American Journal of Surgery. 2005;189(2):129-133.

10. Kiker BF, Zeh M. Relative income expectations, expected malpractice premium costs, and other determinants of physician specialty choice. Journal of Health and Social Behavior. 1998;39(2):152-167.

11. Zinn WM, Sullivan AM, Zotov N, et al. The effect of medical education on primary care orientation: results of two national surveys of students' and residents' perspectives. Acad Med. 2001;76(4):355-365.

12. Maiorova T, Stevens F, Scherpbier A, et al. The impact of clerkships on students' specialty preferences: what do undergraduates learn for their profession? Med Educ. 2008;42(6):554-562.

13. Ward AM, Kamien M, Lopez DG. Medical career choice and practice location: early factors predicting course completion, career choice and practice location. Med Educ. 2004;38(3):239-248.

14. Stagg P, Greenhill J, Worley PS. A new model to understand the career choice and practice location decisions of medical graduates. Rural Remote Health. 2009;9(4):1245.

15. Crossley ML, Mubarik AA. Comparative investigation of dental and medical student's motivation towards career choice. $\mathrm{Br}$ Dent $J$ 2002;193(8):471-473.

16. Sharon E Straus, Christine Straus, Katina Tzanetos. Career Choice in Academic Medicine: Systematic Review. $J$ Gen Intern Med. 2006;21(12):1222-1229.

17. Saadah Sulong, Deirdre McGrath, Paul Finucane, et al. Studying medicine - a cross-sectional questionnaire-based analysis of the motivational factors which influence graduate and undergraduate entrants in Ireland. JRSM Open. 2014;5(4):2042533313510157.

18. Harth SC, Biggs JSG, Thong YH. Mature-age entrants to medical school a controlled study of sociodemographic characteristics, career choice and job satisfaction. Med Educ. 1990;24(6):488-498. 